DOI: 10.24234/miopap.v20i2.403

Vahan SARGSYAN

Srbuhi GEVORGYAN

Lilit GEVORGYAN

\title{
SOCIO-PSYCHOLOGICAL ANALYSIS OF FACTORS INFLUENCING CHESS EDUCATION
}

\begin{abstract}
Armenia has adopted chess in primary school program since 2011, and different types of research have been conducted to evaluate the effectiveness of this implementation. One of the questions to be addressed after chess adoption is: "What are the main and contextual factors of the effectiveness of that implementation?", or "How these factors have been changed?". The article tries to answer those questions conducting correlational research on representative sampling of Armenian students, their parents and teachers.
\end{abstract}

Key words: chess knowledge assessment, divergent thinking, correlational analysis, progress in chess, teaching and learning chess.

The purpose of the present research is data collection and analysis to examine the factors which can influence teaching and learning chess in Armenian schools.

The "Chess" Scientific Research Institute of the Armenian State Pedagogical University initiated and carried out "chess knowledge assessment" research nationwide.

The objectives outlined in the research were:

- to find out the current state of chess-playing skills in different provinces of the country;

- to identify the connection between the results of the subject of chess with different factors of general education;

- to reveal various connections and interactions between chess learners' academic achievements and attitudes towards the subject;

- to find out the difficulties of learning chess and their possible psychological 
reasons.

In our previously carried out research, we did detect a variety of meaningful correlations between the progress level in chess and contextual factors, for instance, the lesson preparation conditions, pupils' integration level during chess lessons, students' school motivation, etc. Of course, we do bear in mind also the fact that the skill to achieve checkmate in two moves is correlated with teachers' pedagogical impact during chess lessons (Mirzakhanyan, at all 2016, p. 38).

As it has been revealed, "there is a strong correlation between chess grades and pupils' reflective and deep styles of learning. Based on these results, we may infer that pupils are very "pragmatic" and they have to develop those skills which could be assessed better by teachers. Therefore, this fact can be indirectly interpreted as evidence of chess as a subject that promotes thinking and reflection. We can state that these students are more likely to set their own learning goals trying to make sense of the respective learning material. They are more motivated than on average, and they tend to build their own learning path giving meaning to what they need to remember" (Sargsyan, Avetisyan, 2019, p. 135).

Researchers have discovered that during chess lessons and games proper, the convergent and divergent types of thinking appear to be combined, which determines the role of chess in primary school as an intellectual game: the convergent and divergent thinking constitute the immediate part of the three-dimensional model of intellect. Depending on the situation, it is possible that thinking will shift from divergent to convergent or the other way around, which are inclusive, typical and beyond stereotyped thinking (take the renowned chess players who always tended to go beyond standard algorithms and stayed in the chess history).

Hence, it is necessary to study in parallel the facts of the predominance of divergent thinking in children with high chess-playing skills, as high results could not be achieved in the case of convergent thinking. So, there is a need to rethink teachers' training by activating divergent thinking (Gevorgyan S. Karapetyan V., at all,2019, p. 29).

The research data suggest that teachers need to deepen their knowledge of the peculiarities of age psychology and patterns, to get to know the student, his emotional world, emotional states, etc.

Considering the problem of teaching chess in the context of experience, motivation and modelling processes, the staff of the research institute 
(Gevorgyan,Karapetyan, 2019) have also tried to prove that during the chess game the primary school student's independent searching (situation analysis, defence organization, response, etc.) motivates his cognitive activity, especially in the process of choosing rational tactical moves appropriate to the situation. The resource of motivation is revealed in line with the provision of methodological saturation, as independent searching works emerging in the conditions of a chess game (as a joint activity) (Sargsyan V., 2019).

Research methods: In order to find the impact of many factors on chess education in Armenia, empirical research has been conducted. During the research, the following methods and tools of quantitative and qualitative research have been applied: questionnaire, test, practical research.

Questionnaires were prepared for the beneficiaries - pupils, teachers, parents. The questions included were about the child's chess experience, parents' attitude towards the chess subject, the teacher's effectiveness in teaching chess. Psychologists, chess players, teachers took part in compiling the questionnaires, who clarified and discussed each task to get a definite version.

In addition to the above mentioned, a test on the chess knowledge was compiled with the purpose to determine the level of knowledge acquired by pupils during the three years of learning chess.

It is noteworthy that the teachers' questionnaire was addressed to the chess teachers who taught chess to the $4^{\text {th }}$ graders of the previous academic year.

The questions mentioned in the questionnaires were formulated in a way to exclude the possibility of double answers: all the questions required a definite answer, which allowed to get a real picture for further analyses.

The survey questionnaires were maximally adapted to the pupils so that both the questionnaires for them and their parents were produced in individual brochures, thus facilitating both the pupils' and parents' completion of the questionnaires and the data entry process.

The questions in one of the pupil's questionnaires were aimed at gaining an idea of their mental processes, and the chess test helped to understand how chess affects their development.

The survey was conducted by random sampling with the participation of all provinces of the Republic of Armenia, including the capital city - Yerevan. There were 40 schools selected, of which 2 schools from Aragatsotn region, 3 from Ararat region, 
3 from Armavir region, 4 from Kotayk region, 2 from Gegharkunik region, 2 from Shirak region, 2 from Tavush region, 2 from Lori region. 2 schools from Syunik region, 1 school from Vayots Dzor region, 17 schools from the capital Yerevan. As part of the research practice, the students of the Faculty of Education and Psychology of the ASPU after Kh. Abovyan joined the research, and they had an opportunity to choose 10 schools and conduct the research in the selected schools, therefore. As a result, about 500 students from 50 schools, 500 parents, 50 teachers participated in the republican research.

Although the sample, as mentioned, was random, the principle of representation was preserved in it as much as possible; that is urban, rural medium and small schools were included from all regions.

It should be mentioned that, before the primary research, a pilot phase was conducted at basic school number 57 next to Khachatur Abovian ASPU with students, parents, and teachers, after which some changes took place in the pupil's questionnaire, more specifically, it was suggested to formulate the statements expressing positive thoughts only, for example, "My teacher does not give me interesting assignments" (with 4 possible answers: "I agree", "I rather agree", "I agree a little", and "I do not agree") was rephrased to make a positive statement - "My teacher gives me interesting assignments", which, according to the experimental research, was more understandable for pupils.

Within the scope of qualitative methods, the action research methodology was chosen, which made it possible to compare the statistical data with the information obtained during the training and discussions of chess teachers, which significantly contributed to the increase of information reliability.

After receiving the completed questionnaires within ten days, the research team proceeded to enter the data and create a database, which enabled the identification of correlation links.

The sampling of the research is presented below (see Diagram 1).

Diagram 1 


\section{Sampling}

- Teacher Parent Pupil

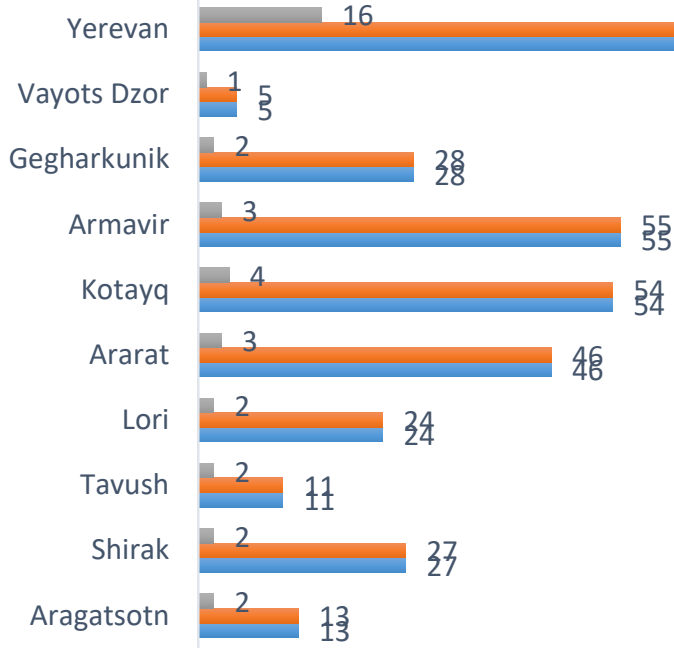


Research results:

\begin{tabular}{|c|c|c|c|c|c|c|c|c|c|c|c|c|c|c|c|c|c|c|c|c|c|c|c|c|}
\hline & 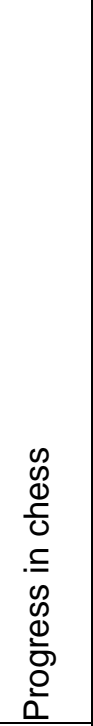 & 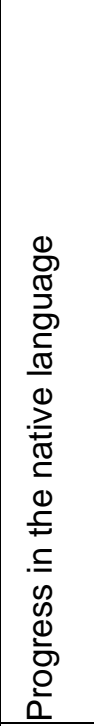 & 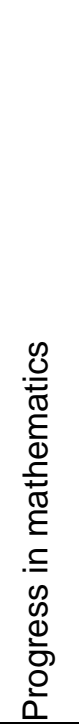 & 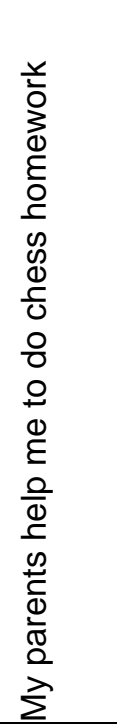 & 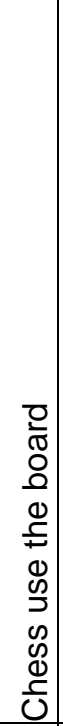 & $\begin{array}{l}\mathscr{D} \\
\Phi \\
\frac{D}{0} \\
\frac{\mathbb{\sigma}}{\alpha}\end{array}$ & 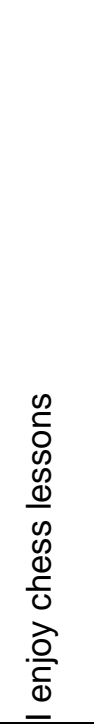 & 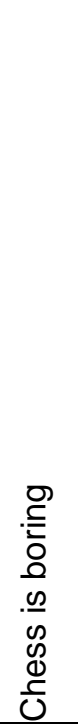 & 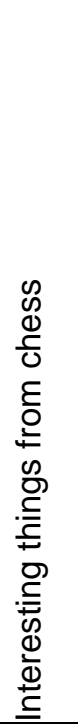 & 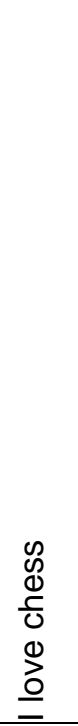 & 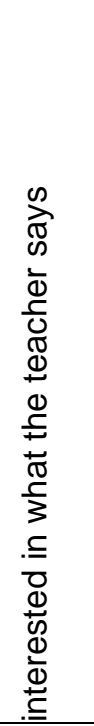 & 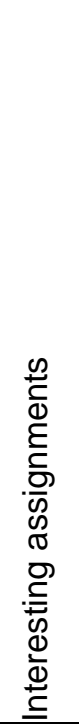 & 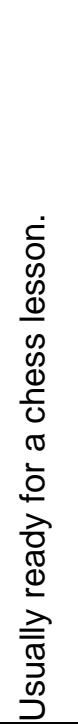 & 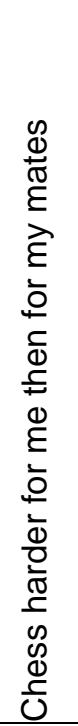 & 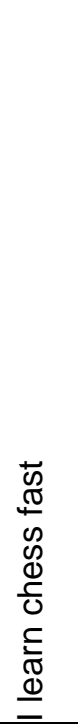 & 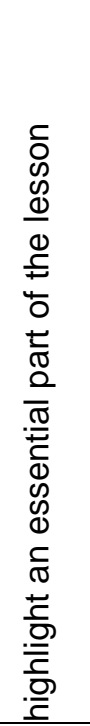 & 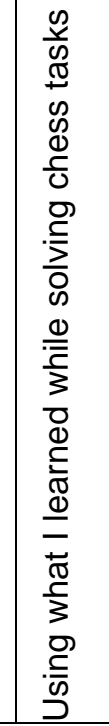 & 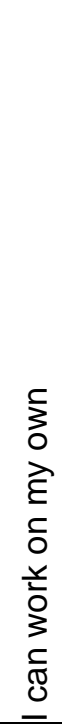 & 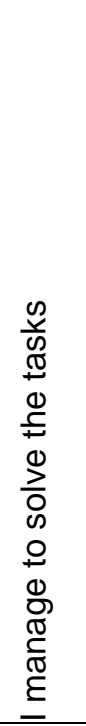 & 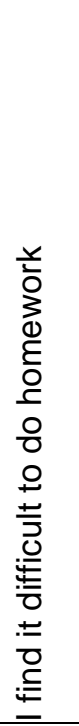 & 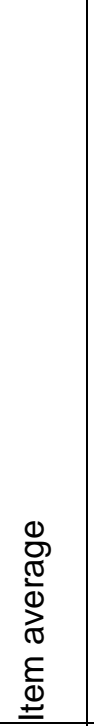 & 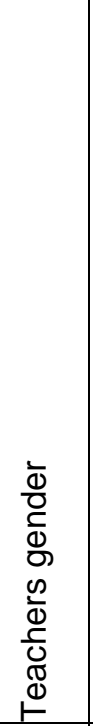 & 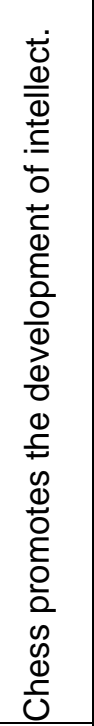 & 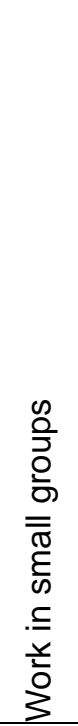 \\
\hline Progress in chess & 1,00 & 0,34 & 0,44 & $-0,07$ & 0,05 & $\cdot 0,10$ & $\overline{0,20}$ & $-0,07$ & $\overline{0,15}$ & $\overline{0,17}$ & 0,09 & $\overline{0,10}$ & 0,19 & $-0,25$ & $\overline{0,36}$ & 0,31 & 0,28 & 0,112 & $-\overline{0,11}$ & $-\overline{0,24}$ & $-\overline{0,20}$ & 0,03 & 0,00 & $-0,01$ \\
\hline $\begin{array}{l}\text { Progress in native } \\
\text { language }\end{array}$ & 0,34 & 1,00 & 0,53 & 0,01 & D, 2 & $-0,13$ & 0,08 & $-0,06$ & 0,06 & 0,03 & 0,06 & 0,13 & 0,09 & $-0,09$ & 0,20 & 0,20 & 0,17 & 0,02 & $-0,09$ & $-0,14$ & $-0,15$ & $-0,01$ & $-0,07$ & 0,14 \\
\hline Progress in math & 0,44 & 0,53 & 1,00 & $-0,09$ & $\mathbb{N} \mathbb{N}$ & $-0,12$ & 0,16 & $-0,08$ & 0,04 & 0,04 & 0,04 & 0,02 & 0,10 & $-0,15$ & 0,31 & 0,22 & 0,22 & $\cdot 0,9$ & $-0,16$ & $-0,14$ & $-0,14$ & 0,05 & 0,02 & 0,10 \\
\hline $\begin{array}{l}\text { Parents help with } \\
\text { doing homework }\end{array}$ & $\begin{array}{l}-0,07 \\
\end{array}$ & \begin{tabular}{|l|l|}
0,01 \\
\end{tabular} & $-0,09$ & 1,00 & 0,06 & 0,17 & $-0,10$ & 0,26 & 0,03 & $-0,05$ & 0,03 & 0,09 & 0,08 & 0,16 & $-0,08$ & $-0,07$ & $-0,03$ & 0,31 & 0,22 & 0,20 & 0,07 & $-0,08$ & $-0,02$ & 0,03 \\
\hline $\begin{array}{l}\text { Chess use the } \\
\text { board }\end{array}$ & 0,05 & 0,02 & $-0,03$ & 0,06 & 1,0 & 0,34 & 0,01 & 0,00 & 0,01 & 0,10 & 0,05 & 0,00 & $-0,05$ & $-0,04$ & 0,07 & 0,05 & $-0,01$ & 0,01 & 0,01 & 0,00 & $-0,03$ & 0,02 & 0,02 & $-0,01$ \\
\hline Play chess & $-0,10$ & $-0,13$ & $-0,12$ & 0,17 & 0.34 & 1,00 & $-0,08$ & 0,06 & $-0,02$ & 0,00 & $-0,05$ & $\cdot 0,08$ & $-0,08$ & 0,08 & $-0,06$ & $-0,16$ & $-0,10$ & 0,03 & 0,09 & 0,12 & $-0,06$ & 0,00 & 0,13 & $-0,20$ \\
\hline $\begin{array}{l}\text { I enjoy chess } \\
\text { lessons }\end{array}$ & 0,20 & 0,08 & 0,16 & $-0,10$ & 0,01 & $-0,08$ & 1,00 & $-0,23$ & 0,39 & 0,51 & 0,32 & 0,29 & 0,38 & $-0,11$ & 0,33 & 0,19 & 0,29 & 0.07 & $-0,03$ & $-0,19$ & $-0,12$ & 0,08 & $-0,02$ & $-0,04$ \\
\hline Chess is boring & $-0,07$ & \begin{tabular}{|l|}
$-0,06$ \\
\end{tabular} & $-0,08$ & 0,26 & 0,0 & 0,06 & $-0,23$ & 1,00 & $-0,12$ & $-0,24$ & $-0,16$ & $-0,12$ & $-0,09$ & 0,32 & $-0,14$ & $-0,07$ & $-0,08$ & 0,25 & 0,12 & 0,39 & 0,12 & $-0,12$ & $\begin{array}{l}-0,07 \\
\end{array}$ & 0,04 \\
\hline
\end{tabular}




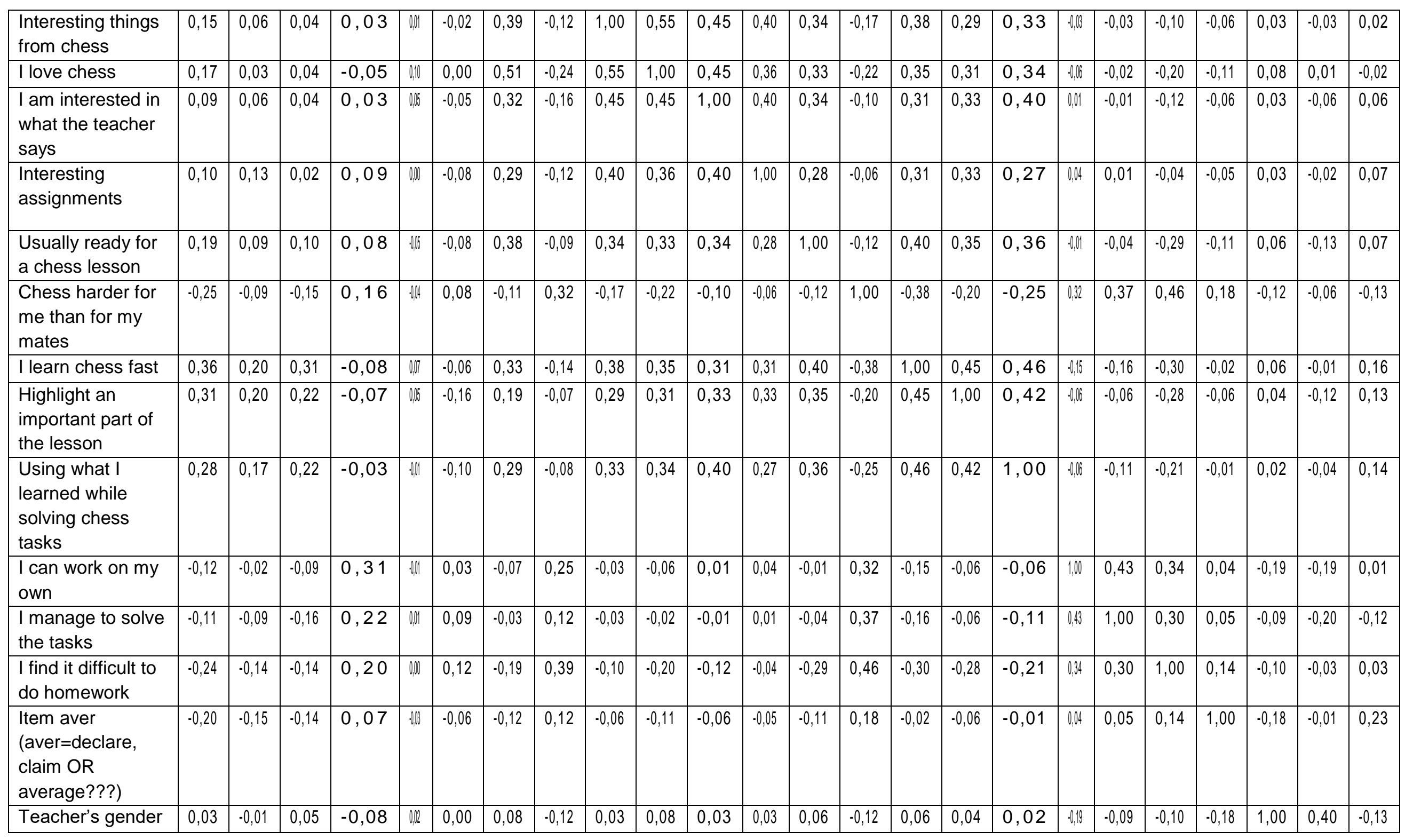




\begin{tabular}{|c|c|c|c|c|c|c|c|c|c|c|c|c|c|c|c|c|c|c|c|c|c|c|c|c|}
\hline $\begin{array}{l}\text { Chess promotes } \\
\text { the intellect }\end{array}$ & 0,00 & $-0,07$ & 0,02 & $-0,02$ & 0,02 & 0,13 & $-0,02$ & $-0,07$ & $-0,03$ & 0,01 & $-0,06$ & $-0,02$ & $-0,13$ & $-0,06$ & $-0,01$ & $-0,12$ & $-0,04$ & 0,19 & $-0,20$ & $-0,03$ & $-0,01$ & 0,40 & 1,00 & $-0,10$ \\
\hline $\begin{array}{l}\text { Work in small } \\
\text { groups }\end{array}$ & $-0,01$ & 0,14 & 0,10 & 0,03 & $\mathbb{N}$ & $-0,20$ & $-0,04$ & 0,04 & 0,02 & $-0,02$ & 0,06 & 0,07 & 0,07 & $-0,13$ & 0,16 & 0,13 & 0,14 & 0,01 & $-0,12$ & 0,03 & 0,23 & $-0,13$ & $-0,10$ & 1,00 \\
\hline
\end{tabular}

All research data have been analysed with the help of the statistical software Statistica 12.

The correlational analysis has been carried out. The inter-correlation matrix has been created - with 97 factors inter-correlated. 
"The average score of chess test" which means the average result of chess knowledge is positively correlated with the "teacher's gender" $(-0.18)$ and "small group work" (0.23).

"The teacher's gender" is positively correlated with the "impact of chess on the development of intellect" (0.40).

"Progress in chess" is in a positive correlation with "progress in native language" (0.43) and "mathematics" (0.44), "learning chess fast" $(0.36)$, with the "ability to distinguish the main idea" (0.31) and "using what I learned while solving chess tasks" (0.28). This fact has been revealed in our previous work too (Sargsyan, Avetisyan., 2019), which can be interpreted as indirect evidence of increasing the role of chess as a school subject.

"Parents' help with homework" is positively correlated with "working independently" (0.31), "successfully problem-solving" (0.22), and "doing homework with difficulty" (0.20).

As it was expected "considering chess as boring" is positively correlated with "chess being more difficult than other subjects" (0.32), "being able to work independently" $(0.25)$, and "doing homework with difficulty" (0.39).

"Learning interesting things from chess" is positively correlated with "being relaxed in chess lessons" (0.39), "teachers' clear explanation" (0.42). Thus, we suppose that teachers' explanation clarity is one of the central and most important factors for students' motivation for learning chess. In a sense, the positive correlations between "loving chess" (0.55) and "teacher's clear explanation" (0.4), "being interested in what the teacher says" (0.45), "performing interesting tasks" (0.40), "being usually ready for lessons" (0.34), "learning chess fast" (0.38) and "distinguishing important things from secondary" $(0,29)$, "solving tasks successfully"(0.33).

"Being interested in what the teacher says" is in a positive correlation with "solving interesting tasks" (0.40), "usually being ready for lessons" $(0.34)$, "learning chess fast" (0.31), "distinguishing the important from the secondary" (0.33), "using what I learned while solving chess tasks" (0.40).

On the one hand "doing homework with difficulty" is in a positive correlation with "being chess boring" (0.39), and "thinking about other things in a chess lesson" (0.35). But on the other hand, the factor "doing homework with difficulty" is correlated with "chess being more difficult than other subjects" (0.5), "being able to work independently (0.33), "successfully solving the problems" $(0,3)$. Therefore, we can state that difficulties with homework make chess tasks boring for a number of students, but it also could become challenging for many others who might be good chess problem solvers. It also has a negative correlation with "easily performing complex chess tasks" $(-0,31)$, with the 
"teacher's consideration that the student is strong in chess" $(-0,38)$.

"Successfully solving problems" is in a positive correlation with "difficulty of doing homework" (0.30), "thinking about things that are not related to the lessons" $(0,2)$. This correlation is not very high and statistically significant. But the correlation between solving problems and being able "to work independently is much higher" $(0,42)$ and significant statistically and in methodological aspect too.

At the same time, it has been revealed that "working independently" has a positive correlation with "successfully solving problems" (0.43) and "doing homework with difficulty "(0.34), "chess being more difficult than other subjects" (0.3). After much reflections, we can conclude that these "paradox" results of correlations are convinced by the dual interpretation of independent work. On the one hand, it can be discussed as a positive way of learning and solving problems independently. Nevertheless, it could also be interpreted as a lack of pedagogical support and consequently, weakness in chess, difficulties in learning chess, etc.

The next group of factors have been outlined after the correlational analysis is mostly referred to students' motivation for learning chess. For instance, the factor "feeling calm in chess lessons" is in a positive correlation with the "student being interested in what the teacher says" (0.39), "being interested in chess" $(0,51)$, "being interested in material provided by the teachers" (0.32), "usually being ready for the lessons" $(0.38)$, “learning chess fast” (0.33).

"Usually being ready for lessons" is positively correlated with "learning chess fast" (0.40), "distinguishing the important from the secondary" (0.35), and "using what I learned while solving chess tasks" (0.36).

So, what can we learn from these connections? What are these inter-correlations speaking about? If we discuss them from the teacher's perspective, we can suppose that student's readiness for the study is usually connected with teacher's classroom management and motivational abilities which become the most important factors for chess education. But being connected with learning chess fast must help teachers to focus not only on the fast but also reflective learning.

As for the correlations which can be interpreted as negative motivational factors we would prefer to discuss the difficulties "chess being more difficult than other subjects" is in a positive correlation with "chess being boring" (0.32), "doing homework with difficulty" (0.46), "being able to work independently" (0.32), and it is in a negative correlation with "learning chess fast" (- 0.38).

The research also found a very interesting fact that "distinguishing the important 
from secondary" is in a positive correlation "using what I learned while solving chess tasks" (0.42). This means that the students believe that when they study how to identify the main, it allows them to solve chess problems more effectively. This fact is also can be discussed as a supporting idea of chess education quality enhancement and can be used in teachers' performance evaluation process. Actually, when teachers help students to solve different chess tasks and problems, applying a wide range of technics, students believe that they become more effective problem solvers. In other words, teachers' competencies have their strong impact on the students' self-efficiency, which can be considered as one of the most important factors of students' motivation.

\section{Conclusions}

1. Chess as an educational tool is widely used as an important way for developing intellectual skills of schoolchildren. This belief appears to be more spread among female than male teachers.

2. Students' progress in chess is mostly in line with their skills and knowledge in native language and mathematics at primary-school level.

3. The role of chess as a school subject has continuously been increasing while pupils have been learning to implement chess skills for developing their problem-solving skills. In fact, when teachers help students to solve different chess tasks and problems, applying a wide range of technics, students believe that they become more effective problem solvers.

4. The development of students independent learning skills and the implementation of working-in-mall-groups skills, as well as other interactive and reflective teaching / learning methods, are becoming a significant factor for developing problem-solving skills through chess.

5. Teachers' classroom management and motivational abilities become the most critical factors for chess education. Nevertheless, it is commendable that teachers focus not only on quick acquisition/assimilation but also reflective and deep learning. Teachers should take into account that students' motivation is also confirmed by the level of difficulty of chess tasks and homework. Hence, perceiving chess as more difficult than other subjects can have a negative impact on their progress in chess in general.

\section{References}

Mirzakhanyan R., Gevorgyan S., Sargsyan V., Daveyan H. (2017). Analysis of the Efficiency of Teaching Chess in Schools. Sociology Study, 7(1), 36-42. 
Gevorgyan S.,Karapetyan V., at all (2019). Regular manifestations of divergent thinking in the process of discovering chess skills. Current state and development trends of chess education. International conference. Tsakhkadzor. 22-29.

Sargsyan V. (2019). The effectiveness of chess teaching in the context of basic psychological directions, Current state and development trends of chess education. International conference. Tsakhkadzor. 72-77.

Sargsyan V. Avetisyan M. (2019). Learning styles and teaching strategies at chess lessons. Current state and development trends of chess education. International conference. Tsakhkadzor.131-135. 